\title{
CFD Research on Car Body
}

\author{
S.Srinivasarao, V.M.Lakshamaih
}

\begin{abstract}
In the design of the car body we need take consideration of cost and comfort for the customer now a car body manufacturing is very difficult due to the compotators the customer will the efficiency of the car as well as the shape design of the car the efficiency car is depends on the internal combustion engine as well as the aero dynamic design of the body the aero dynamic design of the car is the most critical aspect in car design

In this paper we introduced the aero dynamic flow analysis of the 3d car model to evaluate the aerodynamic design parameter. we design the car model by using the catiav5r20 and we did cfd analysis on car body by using the Ansys 14.5 we calculate the velocity and pressure on car body.
\end{abstract}

Keywords: Aerodynamics, CFD, Designing, Ansys, catia.

\section{INTRODUCTION}

Now a days the car body design is the most difficult phenomena in the competitive world why because customer will see the efficiency of the car as well as the body shape of the car the efficiency of the car will depends on the internal combustion engine as well as the aerodynamic design of the car body

An automotive aerodynamic is the study of the aerodynamic forces on the road vehicles the main aim of the aerodynamic study is to decrease the drag force on the automotive vehicle its also decrease the wind noise and the lift forces.

Lift and Downforce From Over Body Flow

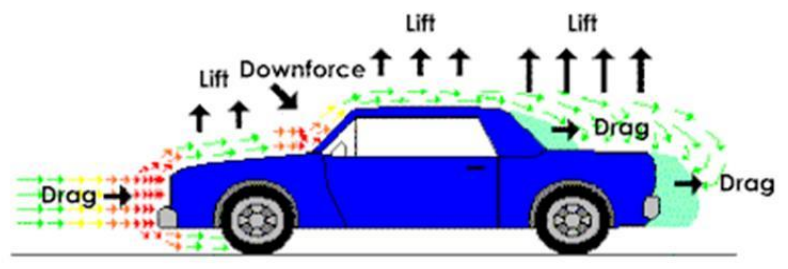

Fig1 Aerodynamic Forces on Car Body

\section{LITERATURE REVIEW}

The following literature was takesn from the different journal which we taken as reference to do the this project most of the literature shows the subject of the air flow analysis on the car body's

1. In the year of 2015 ramya and hemanth kumar from Visakhapatnam Andrapradesh they worked on the design and air flow analysis of the passenger car they conclude that drag force acting on the car body In parabolic manner with respect of the velocity of

Revised Version Manuscript Received on July 10, 2019.

S.Srinivasarao, M.Tech (CAD/CAM), Dept. of Mech, Newton's Institute of Science And TechnologyAlugurajupally, Macherla, Guntur Dist, Andhra Pradesh, India.

V.M.Lakshamaih, Assistant Professor Dept. of Mech, Newton's Institute of Science And TechnologyAlugurajupally, Macherla, Guntur Dist, Andhra Pradesh, India. the car they did two car body model in this projects i.e. SUV and sedan model in that they observe the result the drag force acting on the SUV model is lesser then the sedan model

2. in the year of 2018 R.Varun and Dr sankar from the NCREC Kerala they worked on the cfd analysis of the car body by using the Ansys fluent in that project they are concluding that by their design they decrease the drag force on the model they compare the result of two models i.e. existed model and modified model the drag force on the modified model is lesser then the existed model.

3. in the year of 2017 Vikas V. Chaurasiya, Deepak B. Kushwaha and Mohd. Raees from the Andrapradesh they worked on the aerodynamic analysis of automotive vehicle in this project they did design car model by using the solid works and did analysis by using the gambit fluent.and they calculate static pressure vortices turbulence kinetic energy .

\section{INTRODUCTION TO CATIA}

CATIA is simply know as computer -aided - design which invented by the dassult systems in the year of the 1977 as parent company with the participate company as IBM in our technical stream we have so many $3 \mathrm{~d}$ cad modeling software like pro-e, solid works, uni-grphics, solid work etc ...but coming catia it is very easy and clear then all the software's we we mentioned

Above it has a unique feature like all the software's are parametric based software's but coming to catia it is an feature based software with using one option we can perform only one function. catia is came with nearly 17 different modules which used in different fields .

In aerospace design they will use catia tool for the surface design why because this one is flexible tool for the surface design by using catia we can perform $2 \mathrm{~d}, 3 \mathrm{~d}$ modeling, drafting, assembly, wireframe, sheet metal design for civil people we have plant design for aerspace we have generative shaper design now a days in medical field also they are using catia for their tool designs.

In recent day the dassult system stared the cam and cae tool in catia so now we doing manufacturing as well as analysis also in catia it self.

In this project we design the chassis frame by using the catia v5 r20 with given dimensions we used part design for the design of assembled all the parts of the chassis frame after completing the part design we went assembly module for the assembly we did assembly of the parts which we designed in part design module. 


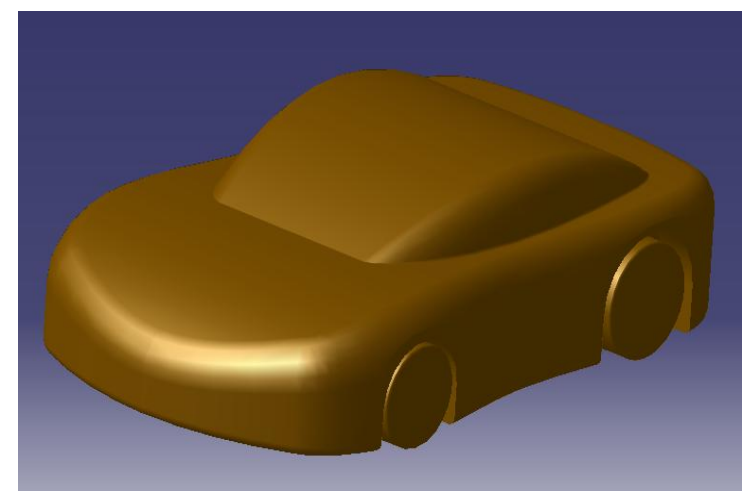

Fig 2 Car Model In Catia

\section{INTRODUCTION TO ANSYS}

The Finite-Element -Method is a numerical technique to find approximate solutions with using partial differential equations it was started with need of solving complex problems in aerospace, mechanical and civil engineering in this structural analysis we will calculate the strength, stiffness of the structure and weight of the structure.

latter on it came with the heat equations vibration analysis flow analysis by using this fem analysis we have different types of fem tools which originated in 1970's i.e. Ansys, hyper mesh, ABAQUS, ls-dyna, nastran etc.......

in this project we used Ansys as a analysis tool. Ansys was invented by the john Swanson in the year of 1970.it made numerous acquisitions for the engineering companies. in this Ansys we have nearly 24 types of analysis. it used for structural, thermal, fluid dynamics electronic design and other analysis.

\section{CFD ANALYSIS \& RESULTS}

In this paper we have a tendency to style Car in catia v5r20 once completion of the look we have a tendency to stared a method in Ansys in this cfd analysis we will analyze the aerodynamic forces in car. in the first step we will import the geometry which we designed in catia. After importing the car model we created the enclosure on the car body in below figure we showed car model and enclosure after the creating the enclosure we create the named sections those are used for the boundary condition. after the that step we did mesh then we enter in to the fluent model ther we will the problem conditions we gave inlet out let and walls of the geometry and we calculate the pressure on the car model and velocity of the air on the car body.

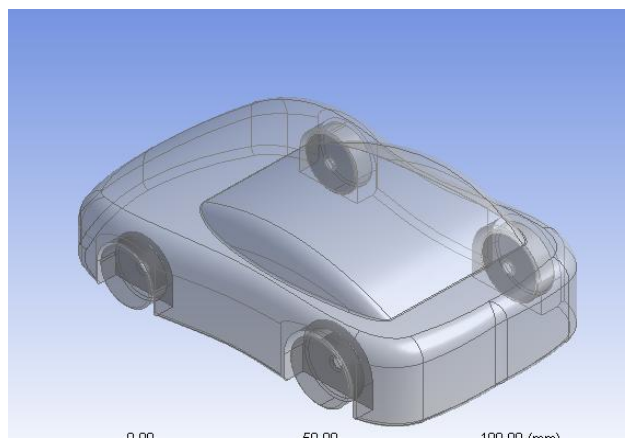

Car Model In Ansys

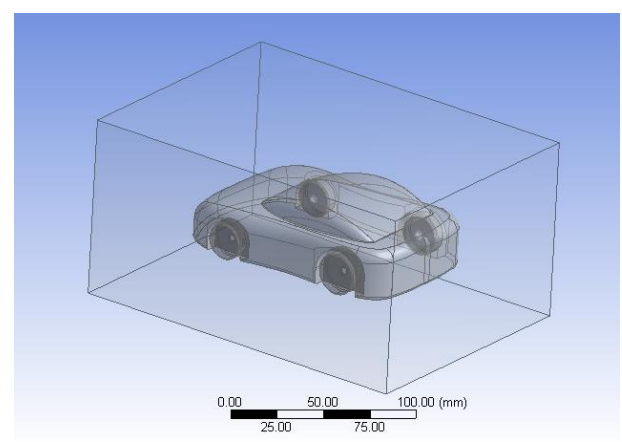

Car With Enclosure

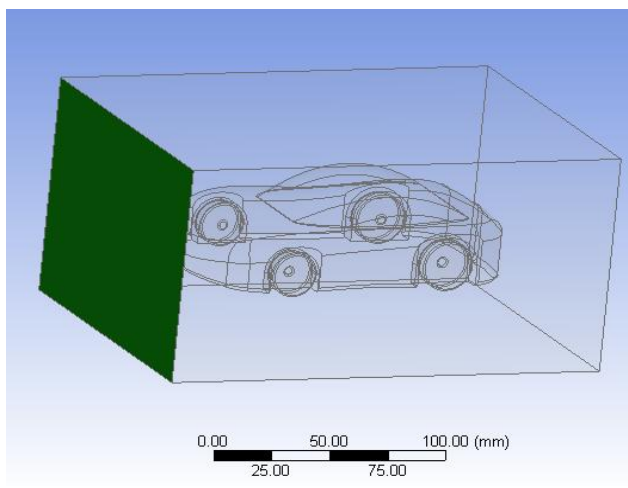

Inlet

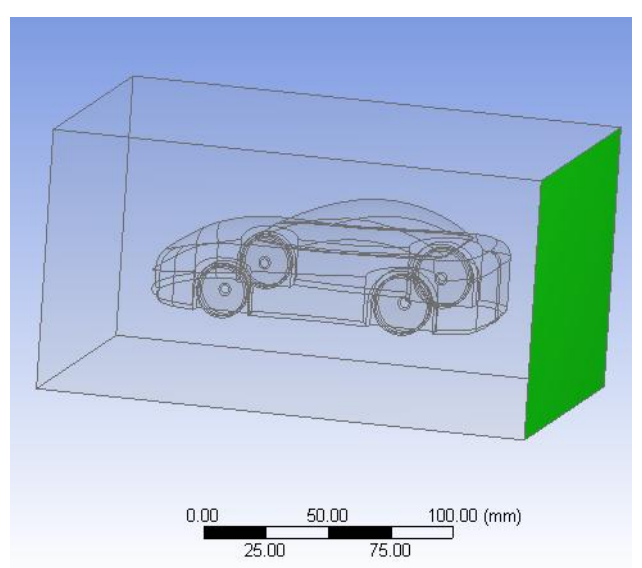

Outlet

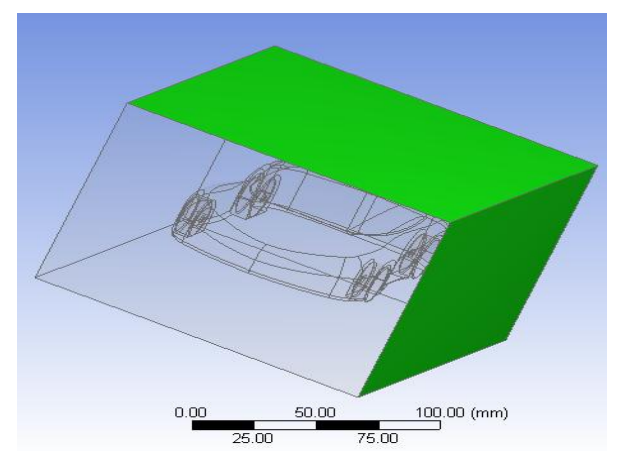

Wall 


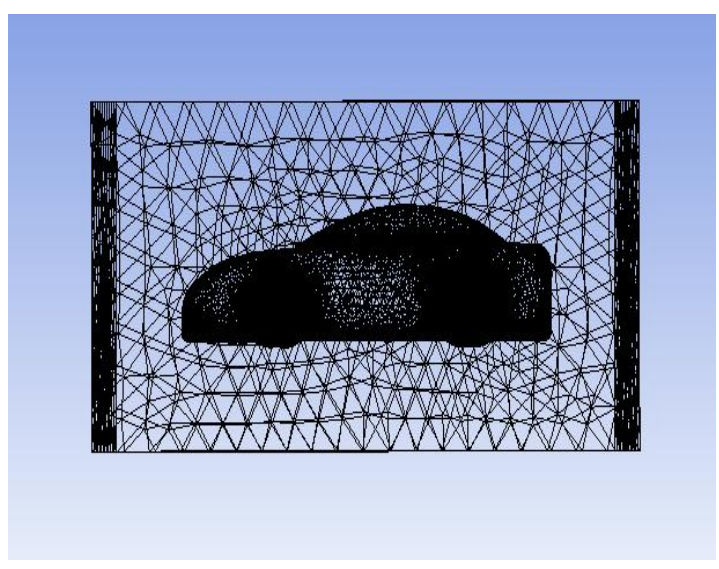

Mesh Model in Ansys

Result And Discussion

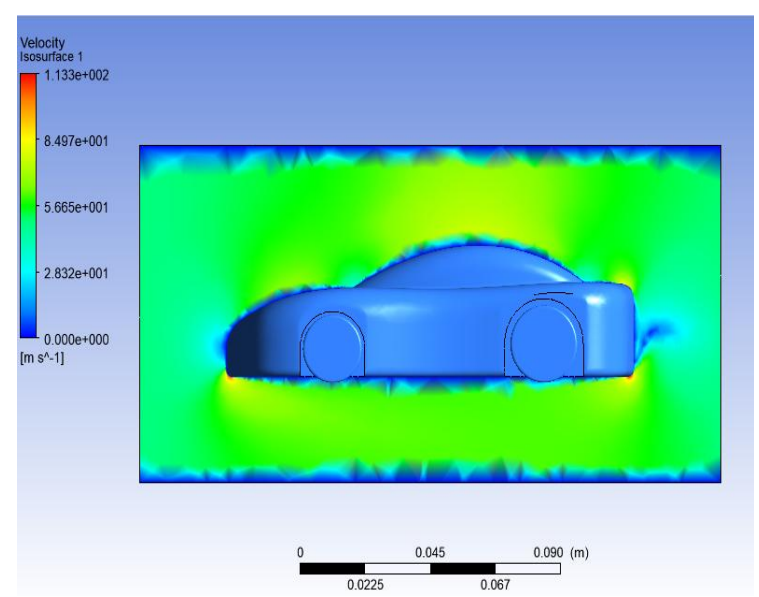

The velocity shape demonstrates a increase in the velocity near to the car. the velocity is observed to be $1.133 \mathrm{e}+002$ on car surface. at wall we are getting low velocity.

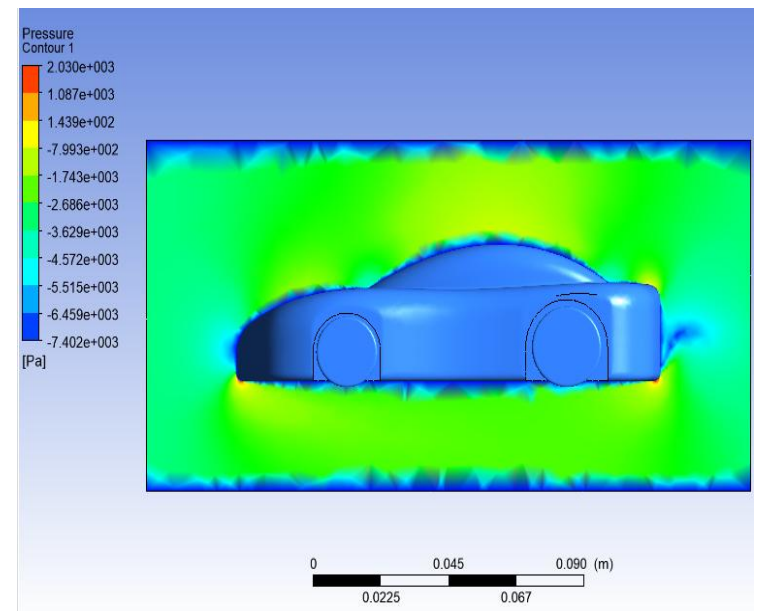

The pressure shape demonstrates a increase in the pressure near to the car. the pressure is observed to be $2.030 \mathrm{e}+003$ on car surface. at wall we are getting low pressure

\section{CONCLUSION}

Approval of numerical outcomes demonstrate that even by limiting the computational space to exit of the car body satisfactory outcomes can be acquired.

From the above result it is demonstrates that pressure and velocity of air increase from walls to car body.

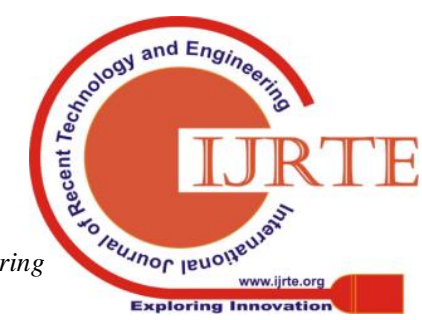

